treatments. The technical details of a single patient with aggressive, FDG-PET avid intracranial GCA who was treated with multiple EVT are discussed. Adequate restoration of cerebral blood flow was achieved in 100\% of interventions and complications included one non-flow limiting dissection $(12.5 \%)$ and two small, delayed, reperfusion hemorrhages (25\%). The authors also report the novel use of intra-arterial calcium-channel blocker infusion (verapamil) as an adjuvant to PTA and as monotherapy, which resulted in immediate improvement in cerebral blood flow (figure 1).

Conclusions Endovascular treatment, including PTA (with or without stenting) and СCB infusion, may be effective in medically-refractory GCA with intracranial arterial stenosis but complication rates are considerable. The efficacy of CCB monotherapy implicates vascular smooth muscle dysfunction in the pathogenesis of intracranial GCA.

Calcium-channel blocker infusion as monotherapy for intracranial giant cell arteritis. Pre-treatment angiography (lateral right internal carotid artery projection) shows severe focal supraclinoid ICA stenosis (curved white arrow, 1A). Post-verapamil infusion (20mg, $15 \mathrm{~min}$ delay) angiogram (1B) shows significant improvement in lumen diameter. Four-dimensional digital subtraction angiography (not shown) confirmed normalization of time-to-peak in the petrous ICA from $4.5 \mathrm{~s}$ to $1.0 \mathrm{~s}$ after verapamil infusion.

Disclosures M. Caton: None. I. Mark: None. A. Baker: None. K. Narsinh: None. V. Halbach: None. S. Hetts: None. D. Cooke: None. R. Higashida: None. C. Dowd: None. W. Smith: None. M. Amans: None.

\section{E-061 AORTIC ARCH DATABASE FOR DEVELOPMENT OF RADIAL-APPROACH DEVICES}

${ }^{1} \mathrm{~K}$ Zerebiec, ${ }^{1} \mathrm{P}$ Heidari, ${ }^{2} \mathrm{D}$ Johnson, ${ }^{2} \mathrm{~S}$ Raymond". ${ }^{2}$ Neurology, The University of Vermont Medical Center, Burlington, VT; ${ }^{2}$ Radiology, The University of Vermont Medical Center, Burlington, VT

\subsection{6/neurintsurg-2021-SNIS.156}

Introduction/Purpose In the last 10 years, many practices have transitioned from femoral to a radial-first approach for cerebral angiography. Despite this change in practice, operators continue to use devices, including diagnostic and guide catheters, developed for a femoral approach. To date, only a single radial-specific catheter, the RIST, has come to market. Development of radial-specific devices requires a comprehensive understanding of the geometries, including vessel lengths and angles encountered from a right radial approach. This abstract reports an aortic arch database to assist in radial-specific device development.

Materials and Methods Neck CTAs from 100 consecutive patients acquired on a single emergency department 256 slice CT scanner were analyzed retrospectively. Arch characteristics and measurements were obtained from $1 \mathrm{~cm}$ MIP reformatted images using McKesson PACs. Data included arch type, angles between the innominate artery and the common carotids, angles at the carotid bifurcations, angles of the vertebral artery origins, and distance from the innominate to the right carotid bifurcation and arch to the left carotid bifurcation and left vertebral origin. Statistical analysis was performed using Excel and R.

Results Of the 100 consecutive patients, 1 was excluded due to poor contrast bolus timing. Our database contains 56 female and 43 male patients, average age 63 years old. $45 \%$

\begin{tabular}{lcl} 
Abstract E-061 Table 1 & Aortic arch angles and lengths \\
\hline Angles (degrees) & Mean & $\begin{array}{l}\text { Standard } \\
\text { Deviation }\end{array}$ \\
\hline R vertetebral, R subclavian & 65.8 & 22.9 \\
R common carotid, innominate & 53.5 & 26.4 \\
L common carotid, innominate & 31.1 & 31.1 \\
L subclavian, innominate & 25.9 & 24.8 \\
& & \\
Distances (mm) & Mean & Standard Deviation \\
R carotid bifurcation, & 88.4 & 14.9 \\
innominate & & \\
L carotid bifurcation, arch & 116.0 & 15.5 \\
L vertebral, arch & 38.9 & 7.1 \\
\hline
\end{tabular}

had type II or III arch configuration, 19\% had bovine configuration, and $5 \%$ had a left vertebral artery originating directly from the arch. Vessel angles and distances are detailed in table 1. Angles encountered at the arch from the innominate average from 26-54 degrees with a large range, mostly accessible via a reverse curve catheter.

Conclusions Trans-radial cerebrovascular angiography presents unique anatomical challenges compared to a traditional transfemoral approach. For example, the left vertebral artery is often just beyond the reach of a standard Simmons 2 catheter. The geometries and lengths outlined in this abstract will inform bio-inspired design of radial-specific catheters and other devices.

Disclosures K. Zerebiec: None. P. Heidari: None. D. Johnson: None. S. Raymond: 1; C; The University of Vermont Health Network Medical Group.

\section{E-062 COBALT PLATINUM STENT-ASSISTED COIL EMBOLIZATION OF A BASILAR TIP ANEURYSM IN A PATIENT WITH A TITANIUM ALLERGY}

J Santucci*, A Mahapatra, M Hussain. Cleveland Clinic Foundation, Cleveland, $\mathrm{OH}$

10.1136/neurintsurg-2021-SNIS.157

Introduction Titanium allergies are rare. Most devices used for cerebral aneurysm treatment contain titanium, and titanium allergy can significantly limit treatment options. We discuss a case report of a patient with titanium allergy who underwent stent-assisted coil embolization of a basilar tip aneurysm with a titanium-free device and the pertinent literature review.

Case Report A 57-year-old female with medical history of hypertension, hyperlipidemia, and prior skin intolerance to metal jewelry had a CT angiogram of the head and neck for headaches and hypertension with incidentally found basilar tip aneurysm. Diagnostic cerebral angiogram confirmed the 4.3 $\mathrm{mm} \times 5.3 \mathrm{~mm} \times 5.6 \mathrm{~mm}$ wide necked basilar tip aneurysm. Given her prior skin metal intolerance, she underwent allergy patch testing with positive reaction to titanium oxide. Initially, given the wide-necked characteristic of her basilar tip aneurysm, embolization was planned utilizing WEB device, composed of Nitinol (combination of nickel and titanium). However, given her titanium allergy, an alternative strategy needed to be employed. After reviewing make up of several devices, she underwent a successful stent-assisted coil 